\title{
ESTATUTO DA ASSOCIAÇÃO BRASILEIRA DE ENFERMAGEM
}

\author{
CAPITULO I \\ Da natureza, sede, foro e fins
}

Art. 1. ${ }^{\circ}$ - A Associação Brasileira de Enfermagem (ABEn), sociedade civil, sem fins lucrativos, que congrega os enfermeiros, fundada a 12 de agosto de 1926, sob a denominação de "Associação Nacional de Enfermeiras Diplomadas Brasileiras", é uma entidade de direito privado, de caráter cultural e assistencial e se rege pelas disposições deste Estatuto e do Regulamento Geral.

Art. 2.0 - A ABEn compōe-se de número ilimitado de associados admitidos nos Distritos, sem discriminação de nacionalidade, etnia, cor, credo, sexo, classe social ou política, desde que devida e legalmente habilitados.

Art. 3.0 - A ABEn tem vigência de tempo indeterminado e sede e foro na Capital Federal.

Art. 4..$^{\circ}$ - A ABEn tem como finalidades:

I - congregar os enfermeiros e incentivar o espírito de união e cordialidade entre os membros da classe;

II - promover o desenvolvimento profissional dos associados e do pessoal de outras categorias compreendidas nos serviços de enfermagem;

III - promover o interrelacionamento com associaçōes congêneres, nacionais, estrangeiras e internacionais, visando o aprimoramento e a divulgação da enfermagem brasileira;

IV - divulgar trabalhos e estudos de interesse da enfermagem, e manter um órgão oficial de publicação periódica;

$\mathrm{V}$ - colaborar com as autoridades governamentais, principalmente de educação e saúde, na solução dos problemas afetos à enfermagem;

VI - colaborar com órgãos oficiais de enfermagem na defesa dos interesses da profissão;

VII - instituir e manter obra filantrópica destinada à assistência dos associados idosos, desvalidos ou necessitados de amparo;

VIII - zelar pelos direitos e interesses dos associados;

IX - colaborar com as escolas de enfermagem no desenvolvimento do espírito associativo entre os estudantes, promovendo sua participação nas atividades sócio-culturais programadas;

$\mathrm{X}$ - colaborar para a melhoria da assistência à saúde do povo brasileiro.

$\S 1 .^{\circ}$ - Para alcançar as finalidades propostas, a ABEn poderá valer-se de todos os meios que forem indicados, incluindo a cooperação com instituições nacionais, estrangeiras e internacionais.

§ 2.0 - Caberá à Diretoria da ABEn estabelecer as diretrizes para essa cooperação, bem como para tender ao inciso III deste artigo. 


\section{CAPITULO II}

\section{Da Organização}

Art. 5..$^{\circ}$ - A ABEn terá a seguinte organização:

I - a nivel central:

a) Assembléia de Delegados (AD)

b) Diretoria

c) Secretaria Executiva

d) Conselho Fiscal

e) Revista Brasileira de Enfermagem (RBEn)

f) Centro de Pesquisas de Enfermagem (CEPEN).

II - a nivel estadual:

a) Assembléia Estadual de Delegados (AED)

b) Diretoria Estadual

c) Secretaria Executiva Estadual

d) Conselho Fiscal Estadual

III - a nivel distrital:

a) Assembléia Geral (AG)

b) Diretoria Distrital

c) Conselho Fiscal Distrital.

\section{CAPITULO III}

\section{Das Seções e dos Distritos}

Art. 6. - A ABEn é constituída pelas Seções das Unidades da Federação que, por sua vez, são constituídas de Distritos que congregam os enfermeiros cos municipios, incluindo o da capital.

Art. 7.0 - As Seçōes terão sede nas capitais das Unidades da Federação e os Distritos nos municípios onde forem criados.

$\S 10^{\circ}$ - As Seções serão constituídas com autorização da $\mathrm{AD}$, mediante petição assinada por, no mínimo, 80 (oitenta) profissionais residentes na Unidade da Federação, e encaminhada à Diretoria da ABEn.

§ $2 .^{\circ}$ - Os Distritos serão constituídos com autorização da Assembléia Estadual de Delegados (AED) do Estado ou Território onde estiverem sediados, mediante petição assinada por, no minimo, 40 (quarenta) profissionais, residentes na própria região e encaminhada à Diretoria da Seção.

$\S 3 .^{\circ}$ - A criação dos Distritos deverá ser homologada pela AD.

$\S 4 .^{\circ}$ - As Seções que contarem apenas com o Distrito da capital, adotarão as normas de funcionamento dos Distritos e das Seções, no que couber.

$\S 5 .^{\circ}$ - Os enfermeiros residentes em Estado, Território ou Municipio que, pelo número de profissionais existentes, não comportarem a criação de Distrito ou Seção, poderão filiar-se ao Distrito da sua conveniência.

$\S 6^{\circ}$ - As Seçōes e os Distritos serão identificados pelo nome ou sigla da Associação seguido do nome ou sigla da Unidade da Federação ou do Município sede, conforme o caso.

Art. 8. - A Assembléia Estadual de Delegados (AED) e a Assembléia Geral (AG) são os órgãos deliberativos das Seçōes e dos Distritos, respectivamente. 
$81^{0}$ - As AED são constituídas de delegados escolhidos pelos associados dos Distritos, reunido em $A G$.

8 2.0 - As AG são constituídas de todos os Associados do Distrito.

Art. 9.0 - As Seçōes e os Distritos deverão elaborar normas específicas de funcionamento, em consonância com as disposições estatutárias e regulamentares da ABEn.

§ $10^{\circ}$ - Caberá às Seções e aos Distritos atenderem, nos seus planos de trabalho, às diretrizes emanadas da Diretoria da ABEn.

$82 .^{\circ}$ - As Seções e os Ditritos poderão manter órgão próprio de divulgação de suas atividades.

\section{CAPITULO IV}

Dos Associados

Art. 10 - Os associados da ABEn pertencerão às seguintes categorias:

I - membro efetivo

II - membro benemérito

III - membro honorário

IV - membro especial.

Art. 11 - São membros efetivos os enfermeiros e as obstetrizes amparadas pela legislação vigente, admitidos nos Distritos e quites com a Tesouraria.

\& 1.0 - Poderão ainda inscrever-se como membro efetivo:

I - os enfermeiros e as obstetrizes estrangeiras diplomados no exterior por escola reconhecida no país de origem;

II - os técnicos de enfermagem diplomados de acordo com a legislação vigente.

\& $2^{\circ}$ - os membros efetivos de que trata o parágrafo anterior gozarão dos mesmos direitos e privilégios dos demais, ressalvada a eleição para os cargas de que trata o Art. 25, incisos I e II.

Art. 12 - São membros beneméritos aqueles que tenham feito doação de bens ou prestado serviços relevantes à Associação e aos quais a $\mathrm{AD}$, por proposta da Diretoria, resolver render esse tributo.

Art. 13 - São membros honorários aqueles que tenham prestado contribuição relevante à causa da enfermagem nacional aos quais a $\mathrm{AD}$, por proposta da Diretoria, resolver render esse tributo.

Art. 14 - São membros especiais, com direito a voz e sem direito a voto, os estudantes dos dois últimos periodos do tronco profissional comum do Curso de Graduação em Enfermagem e Obstetrícia, que tiverem suas propostas de admissāo aprovadas pela Diretoria do Distrito onde estiver sediada a Escola.

Art. 15 - São direitos dos membros efetivos:

I - votar e ser votado, ressalvado o caso previsto nos $\$ 81 .^{\circ}$ e $2 .^{\circ}$ do Art. 11;

II - eleger delegados, com os respectivos suplentes, para as AD e AED;

III - receber orientação para defesa de seus interesses e direitos;

IV - receber o Boletim Informativo e a Revista Brasileira de Enfermagem;

V - inscrever-se nos Congressos promovidos pela ABEn e pelas associações internacionais às quais a ABEn é filiada. 
Art. 16 - São deveres dos membros efetivos:

I - pagar regularmente a anuidade;

II - participar das discussōes de assunto de interesse da classe, em reuniōes e assembléias;

III - participar efetivamente das atividades da ABEn e trabalhar para o seu desenvolvimento;

IV - zelar pelo bom nome da ABEn;

$\mathrm{V}$ - votar nas eleições gerais, estaduais e distritais;

VI - cumprir as disposiçōes deste Estatuto e do Regulamento Geral;

VII - observar o Código de Etica da ABEn;

VIII - colaborar com a Revista Brasileira de Enfermagem;

IX - comunicar à Diretoria da ABEn todos os atos lesivos ao prestígio da ABEn.

Art. 17 - São direitos dos membros especiais:

I - participar das atividades da ABEn;

II - receber orientação para a defesa de seus interesses e direitos relativos à Associação;

III - receber o Boletim Informativo e a Revista Brasileira de Enfermagem.

Art. 18 - São deveres e obrigaçōes dos membros especiais:

I - pagar regularmente a anuidade;

II - participar das discussōes de assuntos de interesse da classe em reuniōes e assembléias;

III - zelar pelo bom nome da ABEn;

IV - observar o Código de Ética da ABEn;

V - cumprir as disposiçōes deste Estatuto e do Regulamento Geral.

\section{CAPITULO V}

Da Administração da $A B E n$

SEÇĀO I

Da Assembléia de Delegados ( $A D$ )

Art. $19-\mathrm{A} A D$, órgão superior de deliberação da $A B E n$, à qual se subordina a Diretoria, é constituída de:

I - Membros natos;

a) Presidentes das Seções

b) Presidentes dos Distritos

c) Um Delegado Oficial de cada Seção

II - Membros eleitos pela AD ou AG, na proporção de 1 (um) para cada 80 membros efetivos, a partir do 81. ${ }^{\circ}$.

$\$ 1 .^{\circ}$ - Os presidentes de Seções ou Distritos, quando impossibilitados de comparecer, poderão delegar suas funçōes a outro membro da Diretoria Estadual ou Diretoria Distrital, respectivamente.

$\S 2 .^{\circ}$ - O Delegado Oficial será eleito por quatro anos, conjuntamente com seu suplente, por ocasião das eleiçōes estaduais.

§ 3. - Cada delegado escolhido pela AED deverá ter um suplente eleito nas mesmas condiçōes do titular. 
Art. 20 - A AD será presidida pelo Presidente da ABEn e assessorada pela sua Diretoria.

Art. 21 - A AD reunir-se-á em sessão ordinária, por convocação do presidente, uma vez por ano no mínimo e, extraordinariamente, por convocação do presidente ou de um grupo de 100 (cem) associados provenientes de, pelo menos, três seçōes.

Art. 22 - As Sessões da AD serão instaladas, em primeira convocação, com a maioria absoluta de seus membros e, em segunda convocação, meia hora após, com representantes de, metade das Seções existentes.

\& $1 .^{\circ}$ - As decisões da AD poderão ser tomadas pelo voto de no mínimo, dois terços dos delegados presentes.

\& $2^{\circ}$ - Cada Delegado terá direito a um voto, não sendo permitida a delegação de votos.

\& 3.0 - A ausência de um delegado ou de seu suplente a uma reunião da $A D$, sem causa justificada, implicará no seu impedimento por dois anos, para nova escolha pela AED.

Art. 23 - A AD compete:

I - empossar os membros da Diretoria e do Conselho Fiscal;

II - discutir e julgar as contas da Tesouraria;

III - discutir e julgar o relatório anual da Diretoria;

IV - discutir e aprovar os planos e programas da Diretoria;

V - determinar anualmente o "per capita" a ser pago pelas seções;

VI - autorizar a criação de Seções e homologar a criação de Distritos;

VII - julgar os atos da Diretoria;

VIII - destituir a Diretoria, no todo ou em parte, por votação secreta, no caso de irregularidade grave, devidamente comprovada, com o fim de resguardar os interesses da ABEn;

IX - discutir e votar a reforma deste Estatuto;

$\mathrm{X}$ - discutir e julgar outros assuntos de interesse da classe;

$\mathrm{XI}$ - aprovar a indicação de membros beneméritos e honorários da ABEn.

Parágrafo único - Todos os assuntos a serem submetidos à consideração da $\mathrm{AD}$ deverão ser apreciados antes pela Diretoria e por esta encaminhados, salvo os que forem objeto de petição escrita e assinada por, no mínimo 50 (cinqüenta) associados.

Art. 24 - A AD decidirá da dissolução da ABEn, em sessão extraordinária e especialmente convocada para esse fim.

\section{SEÇÃO II}

\section{Da Diretoria}

Art. 25 - A Diretoria, órgão executivo da $\mathrm{AD}$ e de administração, comporse-á de 12 (doze) membros, eleitos em escrutínio secreto, para o exercício dos seguintes cargos:

$$
\begin{aligned}
& \text { I }- \text { Presidente } \\
& \text { II }-10^{\circ} \text { Vice-Presidente } \\
& \text { III }-2 .^{\circ} \text { Vice-Presidente } \\
& \text { IV }-1 .^{\circ} \text { Secretário } \\
& \text { V }-2 .^{\circ} \text { Secretário } \\
& \text { VI }-1 .^{\circ} \text { Tesoureiro }
\end{aligned}
$$


VII -2.0 Tesoureiro

VIII - Coordenadores das Comissōes Permanentes

Parágrafo único - Os cargos da Diretoria são eletivos e não remunerados.

Art. 26 - Além da responsabilidade pela consecução dos fins principais da ABEn, à Diretoria compete:

I - cumprir e fazer cumprir o presente Estatuto e o Regulamento Geral, bem como as determinaçōes da $\mathrm{AD}$;

II - apresentar, discutir e votar as emendas a o Regulamento Geral;

III - aplicar a Política de Trabalho da ABEn;

IV - elaborar o plano global e os programas anuais de trabalho a serem submetidos à aprovação da $\mathrm{AD}$;

$\mathrm{V}$ - representar a enfermagem brasileira, nacional e internacionalmente, ou indicar quem a represente;

VI - indicar representantes junto a movimentos de interesse profissional, no país ou no estrangeiro;

VII - determinar a época e local dos Congressos;

VIII - indicar"o Secretário Executivo e definir suas atribuiçōes;

IX - adotar medidas necessárias à defesa da classe, em consonância com a linha de atuação do Conselho Federal de Enfermagem (COFEn) ;

$\mathrm{X}$ - indicar as coordenadoras das comissões especiais;

$\mathrm{XI}$ - indicar o redator chefe e o gerente da RBEn;

XII - apreciar os relatórios parciais e finais das comissōes permanentes e especiais;

XIII - aprovar as chapas para eleições aos cargos da Diretoria e Conselho Fiscal;

XIV - retirar das chapas os nomes impugnados pelas Seçōes;

XV - determinar o calendário das eleições;

XVI - aprovar o orçamento da ABEn para cada exercício;

XVII - deliberar, nos casos omissos ou urgentes "ad referendum" da AD;

XVIII - apresentar à AD relatório anual de suas atividades.

Art. 27 - A Diretoria reunir-se-á, ordinariamente, 6 (seis) vezes por ano e extraordinariamente quando convocada pelo Presidente ou por 5 (cinco) de seus membros;

$\$ 10^{\circ}$ - As reuniōes da Diretoria serão realizadas, em primeira convocação, com a maioria absoluta de seus membros e, em segunda convocação, quinze minutos depois, com cinco membros presentes.

2.0 - Os membros da Diretoria que faltarem, sem causa justificada, a critério da Diretoria, a três reuniōes ordinárias consecutivas ou a 6 (seis) alternadas durante o mandato, será considerado renunciante.

Art. 28 - O mandato da Diretoria será de quatro anos, podendo seus membros, individualmente, serem reeleitos.

Parágrafo único - No caso de morte ou renúncia de um de seus membros antes de decorridos 3 (três) anos do mandato, a Diretoria determinará a realização de eleição para preenchimento do cargo vago.

Art. 29 - São atribuiçōes do Presidente:

I - promover e coordenar as atividades da ABEn, de modo a que seus fins sejam atingidos; 
II - convocar e presidir reunıes, sessōes, assembléias, congressos e seminários, de caráter nacional;

III - elaborar, com o Secretário Executivo, a agenda para a reunioes;

IV - representar a ABEn ativa, passiva, judicial e extra-judicialmente, podendo constituir representantes legais;

$\mathrm{V}$ - autorizar despesas urgentes, emitir e visar cheques com o $1 .^{\circ} \mathrm{Te}$ soureiro e visar todas as contas financeiras da ABEn;

VI - exercer o direito ao voto de qualidade;

VII - apresentar anualmente relatório das atividades da Diretoria à $\mathrm{AD}$.

Parágrafo único - $\mathrm{O}$ limite das despesas a serem feitas pelo Presidente, sem aprovação da Diretoria, será determinada no Regulamento Geral.

Art. 30 - São atribuições do 1.0 Vice-Presidente, substituir o Presidente em seus impedimentos e ausências e auxiliá-lo em seus trabalhos, por delegação.

Art. 31 - São atribuiçōes do 2.0 Vice-Presidente substituir o $1 .^{\circ}$ Vice-Presidente em seus impedimentos e ausências e auxiliá-lo em seus trabalhos, por delegação.

Art. 32 - São atribuiçōes do 1.0 Secretário:

I - organizar e coordenar os trabalhos da Secretaria;

II - redigir as atas da $\mathrm{AD}$ e das reuniōes da Diretoria e registrá-las quando necessário;

III - entregar, dentro de trinta dias após a posse do novo Secretário, todos os livros e documentos que estejam sob sua guarda;

IV - colaborar com o Presidente na elaboração de planos de trabalho e relatórios;

$\mathrm{V}$ - comunicar aos estabelecimentos bancários, onde haja depósito da ABEn, os nomes do novo Presidente e dos Tesoureiros;

VI - no caso de faltarem o Presidente e os Vice-Presidentes, por morte ou renúncia, convocar a Diretoria para determinar a realização de eleiçōes para preenchimento dos cargos vagas, em qualquer período do mandato.

VII - comunicar às respectivas Seçōes o impedimento de delegados na $A D$, de acordo com o $\$ 3 .^{\circ}$ do Art. 22 deste Estatuto.

Art. 33 - São atribuiçōes do $2 .^{\circ}$ Secretário substituir o $1 .^{\circ}$ Secretário em seus impedimentos e ausências e auxiliá-lo em seus trabalhos, por delegação.

Art. 34 - São atribuiçōes do $10^{\circ}$ Tesoureiro:

I - responsabilizar-se judicialmente, perante à Diretoria da ABEn, pelos valores e importâncias que lhe forem confiados;

II - receber dinheiro, valores e qualquer tipo de legado destinados à ABEn;

III - realizar despesas autorizadas pelo Presidente e pela Diretoria;

IV - fornecer dados ao contador e preparar com ele o balancete mensal do movimento financeiro;

V - apresentar ao Conselho Fiscal, para aprovação, os balancetes e balanço anual, com a respectiva documentação;

VI - encaminhar, bimestralmente, o balancete do movimento financeiro à Diretoria;

VII - depositar os valores e importâncias da Associação em estabelecimentos bancários indicados pela Diretoria;

VIII - apresentar anualmente à $\mathrm{AD}$, após a aprovação pelo Conselho Fiscal, o balanço das contas financeiras; 
IX - entregar ao novo $1 .^{\circ}$ Tesoureiro, no prazo de dez dias após a posse, os bens, documentos e livros sob sua guarda;

$\mathrm{X}$ - emitir cheques com o Presidente;

XI - fazer publicar na REBEn o plano de aplicação orçamentária e o balanço anual.

Parágrafo único - O $10^{\circ}$ Tesoureiro contará com o trabalho de especialista em administração financeira.

Art. 35 - São atribuiçōes do 2.0 Tesoureiro:

I - substituir o $1 .^{\circ}$ Tesoureiro em seus impedimentos e ausências e auxiliálo em suas atribuiçōes;

II - coordenar a Comissão de Finanças.

Art. 36 - O controle financeiro e patrimonial da ABEn será centralizado pela Tesouraria e Conselho Fiscal, cujas normas de funcionamento constarão de Regimento Especial.

SEÇÃO III

\section{Das Comissões Permanentes e Especiais}

Art. 37 - As Comissōes Permanentes da ABEn são as seguintes:

$$
\text { I - Finanças; }
$$

II - Publicaçōes e Divulgação;

III - Educação;

IV - Serviço de Enfermagem;

V - Atividades Científicas e Documentação;

VI - Legislação.

$\S 10^{\circ}$ - O coordenador da Comissão de Finanças será o $20^{\circ}$ Tesoureiro.

$\S 2 .^{\circ}$ - O coordenador da Comissão de Publicações e Divulgação acumulará o cargo de Editor da REBEn.

$\S 3 .^{\circ}$ - Compete ao coordenador de cada comissão escolher 3 (três) membros, no mínimo, para integrá-la.

§ 4..$^{\circ}$ - Os coordenadores das comissões permanentes deverão encaminhar à Diretoria plano global e programas anuais de trabalho.

Art. 38 - Os coordenadores das comissōes permanentes deverão apresentar relatório bimestral à Diretoria.

Art. 39 - As comissōes permanentes da ABEn deverão assessorar as respectivas comissōes das Seçōes e dos Distritos.

Art. 40 - A competência de cada uma das comissões permanentes constará do Regulamento Geral.

Art. 41 - Problemas específicos serão estudados por comissōes especiais indi_ cadas pela Diretoria e desfeitas ao término de seu trabalho, com a apresentação do relatório de atividades.

\section{SEÇÃO IV \\ Dos Órgãos de Divulgação e Pesquisa}

Art. 42 - A Revista Brasileira de Enfermagem (REBEn) é o órgão oficial de divulgação da ABEn e sua organização e funcionamento serão objeto de Regimento Especial. 
Art. 43 - O Centro de Pesquisas de Enfermagem (CEPEn) é o órgão da ABEn destinado a incentivar a pesquisa na área da enfermagem e terá sua constituição e atribuiçōes definidas em Regimento Especial.

\section{SEÇÃO V \\ Da Secretaria Executiva}

Art. 44 - A Secretaria Executiva é o órgão de apoio da Diretoria e terá sua organização e funcionamento determinados no Regulamento Geral.

SEÇÃO VI

\section{Do Conselho Fiscal}

Art. 45 - O Conselho Fiscal será compostos de 3 (três) membros.

Art. 46 - Ao Conselho Fiscal compete:

I - fiscalizar a administração econômica, financeira e patrimonial da ABEn;

II - emitir parecer sobre os balancetes e balanço anual da ABEn.

Parágrafo único - O Conselho Fiscal reunir-se-á ordinariamente para apreciação dos balancetes, antes de cada reunião ordinária da Diretoria e, extraorcinariamente, quando julgar necessário.

Art. 47 - O mandato dos membros do Conselho Fiscal será de 4 (quatro) anos, podendo haver reeleição.

\section{CAPITULO VI}

\section{Das Eleições}

Art. 48 - Todos os membros efetivos da ABEn, quites com a Tesouraria, tem direito a votos nas eleiçōes dos membros da Diretoria e do Conselho Fiscal.

Art. 49 - Para candidatar-se a um desses cargos é necessário ser membro da ABEn há, pelo menos, trềs anos.

Art. 50 - As eleições serão feitas através de votação por chapa.

Art. 51 - As chapas serão organizadas por Comissão Especial, ouvidas as Seções e a estas submeticias pelo menos três meses antes da data marcada para o pleito.

$\S 10^{\circ}$ - Terminado o mandato do Presidente este preencherá automaticamente o cargo de $2 .^{\circ}$ Vice-Presidente.

§ 2.0 - No caso de reeleição do Presidente, o 2.0 Vice-Presidente continuará no cargo.

§ $3 .^{\circ}$ - As chapas de que trata este artigo não poderão conter o mesmo nome para mais de um cargo da Diretoria.

§ $4 .^{\circ}$ - Os candidatos a cargo da Diretoria não poderão concorrer ao Conselho Fiscal.

\$ $5 .^{\circ}$ - Deverão constar de cada chapa apenas um nome de candidato a cada cargo. 
§ 6.0 - As Seções poderão impugnar ou sugerir nomes de candidatos, devendo dar ciência à Comissão Especial de Preparo de Chapas até pelo menos 2. (dois) meses antes do pleito, sem o que a chapa será considerada aprovada.

$\S 7 .^{\circ}$ - A retirada de nomes impugnados pelas Seçōes só poderá ser feita pela Diretoria e em caráter confidencial.

Art. 52 - As eleições dos membros da Diretoria e do Conselho Fiscal da ABEn serão realizadas nos Distritos: em escrutínio secreto, na data determinada no calendário das eleições.

Parágrafo único - As normas e procedimentos das eleiçōes constarão do Regulamento Geral.

Art. 53 - As eleiçōes dos membros das diretorias estaduais e distritais, e dos respectivos conselhos fiscais, serão realizadas por ocasiāo das eleiçōes da A.BEn, obedecendo o calendário estabelecido.

\section{CAPITULO VII}

\section{Do Patrimônio da $A B E n$}

Art. 54 - O patrimônio da ABEn será constituído por:

I - anuidades;

II - receita dos congressos;

III - receita proveniente de contratos ou convênios científico-culturais;

IV — subvenções, doações e legados;

$\mathrm{V}$ - bens móveis e imóveis;

VI - fundos especiais.

Art. $55-\Lambda$ Diretoria é responsável por todos os bens patrimoniais da ABEn.

§ $1 .^{\circ}$ - As Seções e os Distritos deverão submeter os projetos de disposição de bens patrimoniais ao julgamento da Diretoria e à decisão da $\mathrm{AD}$.

$\S 2 .^{\circ}$ - Os recursos financeiros da ABEn serão destinados exclusivamente a açōes que visem a atingir finalidades constantes do Art. $4 .^{\circ}$ deste Estatuto.

\& $3^{\circ}$ - Os atos de lesão ao patrimônio serão julgados pela Diretoria e pela $A D$.

Art. 56 - Os bens móveis e imóveis da ABEn são inalienáveis, exceto em casos especiais, para benefício da própria Associação.

Art. 57 - No caso de dissolução da ABEn, os bens patrimoniais da Associação serão integralmente destinados a obras de assistência aos enfermeiros.

\section{CAPITULO VIII}

\section{Disposições Gerais}

Art. 58 -A ABEn deverá realizar congressos de âmbito nacional ou congressos regionais, pelo menos cada 2 (dois) anos, para discussão e estudo dos problemas profissionais nos campos do ensino e do exercício da enfermagem. 
Parágrafo único - A Comissão Executiva do Congresso, indicada pela Diretoria, compete a organização do certame, observado o disposto no Regimento Especial de Congressos.

Art. 59 - A ABEn destinará $2 \%$ de sua receita bruta, ou mais, a critério da $A D$, à obra filantrópica de construção e manutenção da Casa da Enfermeira.

Art. 60 - Além deste Estatuto e do Regulamento Geral, a ABEn terá tantos Regimentos Especiais quantos forem necessários para dar maior funcionalidade à organização, visando a alcançar os fins a que se propōe.

Art. 61 - A ABEn terá como símbolo um escudo cujas especificaçōes constarão do Regimento Especial.

Art. 62 - Os membros da ABEn não respondem, pessoal ou subsidiariamente, pelas obrigaçōes sociais da Associação.

Art.63 - As disposiçōes contidas no presente Estatuto aplicam-se, no que couber, às Seçōes e aos Distritos.

Art. 64 - Os casos omissos serão resolvidos pela Diretoria.

Art. 65 - O presente Estatuto entrará em vigor na data de sua aprovação pela $A D$.

- O presente Estatuto foi aprovado na $\mathrm{AD}$ realizada no dia 11 de agosto de 1976 na cidade do Rio de Janeiro e registrado. 